\title{
Aortic valve-sparing operation versus Bentall and mechanical aortic valve replacement - midterm results
}

\author{
Sabol $\mathrm{F}^{1}$, Kolesar $\mathrm{A}^{1}$, Jankajova $\mathrm{M}^{2}$, Luczy $\mathrm{J}^{1}$, Holoubek $\mathrm{D}^{2}$, Artemiou $\mathrm{P}^{1}$, Toporcer $\mathrm{T}^{1}$, Jevcakova $\mathrm{J}^{1}$, \\ Valocik $\mathrm{G}^{2}$, Porubcinova $\mathrm{I}^{3}$, Dvoroznakova $\mathrm{M}^{2}$, Candik $\mathrm{P}^{3}$, Jakubova $\mathrm{M}^{3}$, Torok $\mathrm{P}^{3}$, Beres $\mathrm{A}^{1}$, \\ Mistrikova $\mathrm{L}^{1}$, Safar $\mathrm{P}^{1}$, Ledecky $\mathrm{M}^{1}$ \\ Clinic of Cardiac Surgery, East Slovakia Institute for Cardiovascular isease, Inc., Faculty of Medicine Pavol Jozef Safarik \\ University, Kosice, Slovakia. adriankolesar@seznam.cz
}

\begin{abstract}
Objectives: The primary aim of this retrospective study was to evaluate short-term (one-to-six months) and mid-term (six-to-forty-eight months) results of aortic valve-sparing procedures. The second endpoint was to compare the results with the group of patients undergoing mechanical aortic valve replacement during the same period. Methods: Between April 2008 and May 2012 at our institution, we treated 76 patients either with ascending aorta/root aneurysm/dissection or with isolated aortic regurgitation. A total of seventy-six patients undergoing aortic valve surgery.

Results: Analyzed parameters were divided into two parts as function of time. In the first part, i.e. during hospitalization, the mortality, duration of hospitalization, duration of extra corporeal circulation (ECC), and duration of cardiac arrest (CA) were compared and assessed. In the second part, i.e. during monitoring of the patients after their discharge from hospital (one-to-six months, and six-to-forty-eight months), the grade of postoperative AR aimed mainly at the group of aortic valve-sparing operations (subgroups A1, A2, A3), postoperative peak gradient, presence of thromboembolic and bleeding complications, postoperative endocarditis and need for reoperation or hospitalization due to cardiac reasons were analyzed.

Conclusion: Based on our first experience, we believe that in spite of higher technical difficulty, the aortic valvesparing operations can be possibly performed with the same or respectively lower rate of postoperative morbidity and mortality. Presented results show that compared with the aortic valve replacement, the aortic valve-sparing operation is a promising method, and an interesting therapeutic alternative for patients. After proper indications, we consider it to be a method of choice (Tab. 6, Fig. 7, Ref. 28). Text in PDF www.elis.sk.

Key words: aortic root aneurysm, aortic regurgitation, aortic valve sparing operations, leaflet prolapsed, aortic root remodeling, aortic valve reimplantation, external aortic ring.
\end{abstract}

In the past 20 years, the mitral valve-sparing surgery or mitral valve repairs has become a method of choice for patients with mitral regurgitation. It is proved that mitral valve repair provides lower rate of perioperative mortality, lower risk of complications, and better long-term results compared to mitral valve replacement $(1,2,3)$.

The situation is more complicated with aortic valve-sparing operations. These operations are indicated for two reasons. Similarly as in mitral valve repair surgery, the first indication is the aortic regurgitation. The second indication is the aortic root aneurysm, when the operation is indicated as prevention in order to decrease the risk of aortic dissection or perforation (6).

${ }^{1}$ Clinic of Cardiac Surgery, East Slovakia Institute for Cardiovascular isease, Inc., Faculty of Medicine Pavol Jozef Safarik University, Kosice, Slovakia, ${ }^{2}$ Clinic of Cardiology, East Slovakia Institute for Cardiovascular Disease, Inc., Faculty of Medicine Pavol Safarik University, Kosice, Slovakia, and ${ }^{3}$ Clinic of Anestesiology and Intensive Care, East Slovakia Institute for Cardiovascular Disease, Faculty of Medicine, Inc., Pavol Safarik University, Kosice, Slovakia

Address for correspondence: A. Kolesar, Clinic of Cardiac Surgery, East Slovakia Institute for Cardiovascular Disease, Inc., Faculty of Medicine Pavol Jozef Safarik University, Kosice, Slovakia. Phone: +421.904973629, Fax: +421.55 .7891213$
The gold standard in aortic root surgery is the Bentall operation (graft replacement of aortic valve and aortic root), and in the case of isolated aortic valve leaflets disease, it is the replacement of valve with mechanical or biological prosthesis (7).

Aortic regurgitations in adults used to be treated with valve replacements except for the acute onset of severe aortic regurgitation due to aortic dissection. During the surgery of aortic dissection of type A, it is possible to fix the detached valve commissure to the aortic wall with sutures to resolve the aortic regurgitation and preserve the valve. Within the past years there has been an increase in number of publications on successful repairs of many kinds of aortic regurgitations. Therefore the aortic valve-sparing operations have become a more intensive point of surgeons' interest $(8,9)$.

The trend is to perform the aortic valve-sparing operations in younger population to prevent them from various risks related to prosthetic valves. The goal is to eliminate the potential risks factors related to valve replacement by artificial valve prosthesis such as a thromboembolic and bleeding complications associated with permanent anticoagulation therapy. There is also the risk of premature degeneration of biological valves, and prosthetic endocarditis (10). In consideration of performing these operations 
in younger population, there is a high probability of these potential life-threatening complications over the years.

The disadvantages of aortic valve-sparing operations include high technical difficulty, and risk of reoperation due to repair failure. Provided that indications and technical realization are good, it is possible to maintain that the aortic valve and root-sparing operation is an excellent alternative to Bentall operation or aortic valve replacement. The increase in the number of sparing operations has an influence on indications toward the early aortic root replacement $(11,12)$.

\section{Materials and methods}

\section{Patients}

From April 2008 to May 2012, a total of thirty-eight aortic valve and root-sparing operations were carried out. The analyzed group consists of seventy-six patients divided into two groups, A and B, while group B is the control group. All patients participated in the postoperative follow-up. The objective of the analysis was to demonstrate a short-term (one-to-six months) and mid-term (six-to-forty-eight months) aortic valve-sparing operation results. Observed parameters were compared with those in the control group. Selected indication criteria for inclusion in the group were as follows: - the ascending aorta or the aortic root aneurysm/dissection with aortic regurgitation,

- isolated severe aortic regurgitation without aortic stenosis.

The exclusion criteria were as follows:

- the left ventricular ejection fraction less than $40 \%$,

- aortic dissection without aortic regurgitation,

- aortic stenosis,

Tab. 1. Characteristics of subgroups A1-3, B1-3.

\begin{tabular}{lc}
\hline Subgroup & $n$ \\
\hline $\begin{array}{l}\text { A1 elective aortic root / ascending aorta reconstruction for } \\
\text { aortic aneurysm }\end{array}$ & 23 \\
\hline $\begin{array}{l}\text { A2 urgent aortic root / ascending aorta reconstruction for } \\
\text { aortic dissection }\end{array}$ & 10 \\
\hline $\begin{array}{l}\text { A3 elective valve sparing procedure for isolated valve re- } \\
\text { gurgitation }\end{array}$ & 5 \\
\hline
\end{tabular}

B1 elective Bentall procedure for aortic aneurysm

B2 urgent Bentall proceduret for aortic dissection

23

$\mathrm{B} 3$ elective replacement of aortic valve for isolated valve regurgitation

Tab. 2. Patient characteristics in particular subgroups A1-3, B1-3.

\begin{tabular}{|c|c|c|c|c|c|c|c|c|c|}
\hline Subgroup & A1 & $\mathrm{B} 1$ & $\mathrm{p}$ & A2 & $\mathrm{B} 2$ & $\mathrm{p}$ & A3 & B3 & $\mathrm{p}$ \\
\hline Male/women & $19(4)$ & $19(4)$ & - & $10(0)$ & $8(2)$ & 0.13 & $2(3)$ & $3(2)$ & 0.52 \\
\hline Age & $52.4 \pm 12.2$ & $59.3 \pm 12.1$ & 0.02 & $55.9 \pm 15.3$ & $49.6 \pm 14.8$ & 0.13 & $55.9 \pm 15.3$ & $45 \pm 12.5$ & 0.09 \\
\hline NYHA class & $2.1 \pm 0.5$ & $2.2 \pm 0.6$ & 0.4 & $2.2 \pm 0.4$ & $2.4 \pm 0.5$ & 0.17 & $2.4 \pm 0.5$ & $2.6 \pm 0.5$ & 0.28 \\
\hline $\mathrm{EF}(\%)$ & $53.6 \pm 5.9$ & $54.7 \pm 9.2$ & 0.32 & $48.5 \pm 5.3$ & $50.4 \pm 8.3$ & 0.14 & $51.2 \pm 7.5$ & $46.2 \pm 11.1$ & 0.21 \\
\hline Hypertension (\%) & $16(69.6)$ & $17(73.9)$ & 0.74 & $10(100)$ & $10(100)$ & - & $2(40)$ & $2(40)$ & - \\
\hline AR grade & $2.9 \pm 0.9$ & $2.7 \pm 0.7$ & 0.5 & $3 \pm 0.5$ & $3 \pm 0.5$ & 0.5 & $3.4 \pm 0.5$ & $35.2 \pm 2.2$ & 0.27 \\
\hline AA diameter (mm) & $55 \pm 11.1$ & $53.7 \pm 10.2$ & 0.14 & $47.1 \pm 11.0$ & $55 \pm 11.9$ & 0.1 & $34.6 \pm 5.5$ & $35.2 \pm 2.2$ & 0.41 \\
\hline AR diameter (mm) & $49 \pm 8.6$ & $51 \pm 6.3$ & 0.09 & $41.6 \pm 5.0$ & $43.7 \pm 6.7$ & 0.29 & $33.3 \pm 6.2$ & $30 \pm 1.6$ & 0.07 \\
\hline
\end{tabular}

Tab. 3. Morphology of aortic valve in particular subgroups.

\begin{tabular}{lcccc}
\hline \multirow{2}{*}{ Subgroup } & \multicolumn{4}{c}{ Number of aortic valve cusps } \\
\cline { 2 - 5 } & Unicuspid & Bicuspid & Tricuspid & Quadricuspid \\
\hline A1 & 1 & 13 & 9 & 0 \\
A2 & 0 & 3 & 7 & 0 \\
A3 & 1 & 2 & 2 & 0 \\
B1 & 1 & 9 & 12 & 1 \\
B2 & 0 & 2 & 8 & 0 \\
B3 & 0 & 2 & 2 & 1 \\
\hline
\end{tabular}

- history of stroke with residual neurologic disability,

- patients integrated into chronic dialysis program,

- arteria carotis interna stenosis more than $70 \%$.

The first group consisted of thirty-eight patients (group A) undergoing the aortic valve-sparing operation and second group (control group) consisted of thirty-eight patients (group B) undergoing mechanical aortic valve replacement. These two groups were divided into subgroups A1 to A3 and B1 to B3 (Tab. 1) according to the surgery technique and aortic valve regurgitation mechanism.

Patients of subgroup A1 were treated with elective aortic valve and root-sparing operation due to the aortic ascending/aortic root aneurysm. The subgroup A1 was compared with subgroup B1 with patients treated with elective Bentall operation due to aortic root aneurysm.

In subgroup A2, patients with urgent supracoronary replacement of the aorta, and reinforcement of the aortic root wall using glue and aortic valve-sparing operation due to aortic dissection were arranged. The group A2 was compared with subgroup B2, which consisted of patients also with the type A of aortic dissection undergoing the urgent root replacement with mechanical conduit. The operative findings in both subgroups A2 and B2 were comparable. All patients in A2 and B2 subgroups were eligible to undergo either root replacement or supracoronary replacement combined with valve repair.

The patients in subgroup A3 were treated with elective aortic valve repair due to isolated AR. The subgroup A3 was compared with subgroup B3, which also consisted of patients with isolated aortic regurgitation. The elective mechanical aortic valve replacement was performed in subgroup B3. From 2008 to 2012, ten mechanical aortic valve replacements due to isolated AR were performed. Using the propensity score matching method, five patients forming the subgroup B3 were selected. This subgroup was compared with subgroup A3.

Preoperative parameters in each subgroup (A 1-3, B 1-3) are shown in Table 2. The morphology of aortic valve is shown in Table 3.

$\mathrm{EF}$ - ejection fraction of left ventricle; AR - aortic regurgitation; AA - ascending aorta; AR - aortic root 


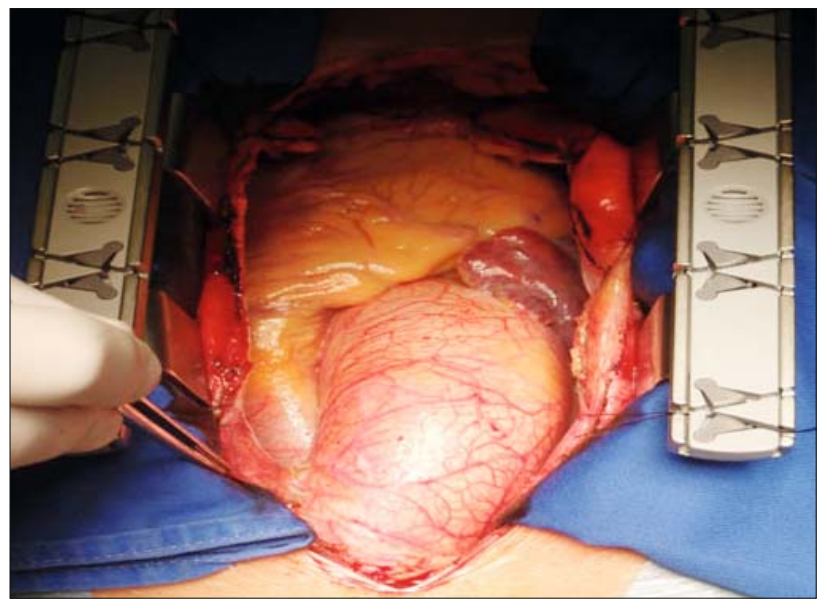

Fig. 1. Perioperative picture of ascending aorta and root dilatation (Clinic of Cardiac Surgery, VÚSCH, Inc., Kosice, Slovak Republic).

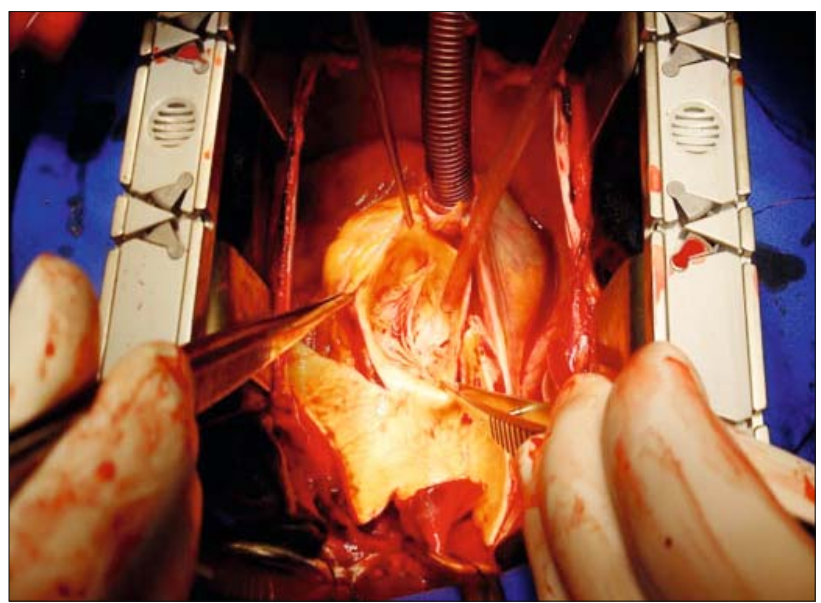

Fig. 2. Perioperative picture of bicuspid aortic valve, type 0 ap (Clinic of Cardiac Surgery, VÚSCH, Inc., Kosice, Slovak Republic).

The subgroups compared were co-equal in observed parameters. Preoperative and postoperative examinations included history, echocardiography and CT imaging.

The most common cause of AR in both groups was the aortic ascending and aortic root aneurysm (Fig. 1). In the case of tricuspid aortic valve, El Khoury's classification (5) was used. To describe the bicuspid aortic valve, Bechtel's classification was used, while the essence lies in the numbers of raphes, and their spatial position to coronary sinuses (13). An ideal type of the bicuspid aortic valve is Type 0ap, which means that the valve is without raphe, and with fusion of the left and right coronary leaflets (Fig. 2).

\section{Observed parameters}

During hospitalization, mortality, duration of hospitalization, duration of extra-corporeal circulation, and cardiac arrest were assessed. In the patient follow up after their discharge from hospital, the postoperative peak gradient on repaired valve or mechanical prosthesis, severity of residual AR, presence of thromboembolic
Tab. 4. Surgical procedures in subgroups.

\begin{tabular}{lccc}
\hline & \multicolumn{3}{c}{ Subgroup A } \\
\hline Surgical procedure & A1 & A2 & A3 \\
Cusp plication & 20 & 4 & 5 \\
Subcommisural annuloplasty & 5 & 7 & 5 \\
Raphé resection & 8 & 0 & 1 \\
Cusp augmentation by pericardium & 3 & 0 & 2 \\
Cusp debridement & 2 & 0 & 0 \\
Cusp free margin enforcement & 1 & 0 & 1 \\
Pericardial patch & 1 & 0 & 1 \\
Supracoronary replacement of aorta & 6 & 10 & 0 \\
Aortic valve reimplantation (David) & 8 & 0 & 0 \\
Aortic root remodelling (Yacoub) & 2 & 0 & 0 \\
Remodelling plus anuloplasty ring CoroNéo & 7 & 0 & 0 \\
\hline & \multicolumn{3}{c}{ Subgroup B } \\
\hline Surgical procedure & B1 & B2 & B3 \\
Bentall procedure with mechanical conduit & 23 & 10 & 0 \\
Replacement of aortic valve with mechanical prosthesis & 0 & 0 & 5 \\
\hline
\end{tabular}

and bleeding complications, and postoperative endocarditis (native/prosthetic), and need for reoperation or hospitalization for cardiac reasons were observed.

\section{Surgical technique}

All operations were done by median sternotomy approach. After the heparin administration, the patients were connected to the extracorporeal circulation via the aorta/arteria (distal ascending aorta or arteria subclavia dextra due to aortic dissection) and with a single venous double staged cannula. Surgical techniques in each group and subgroup are presented in Table 4.

Sixteen patients underwent the supracoronary ascending aorta replacement combined with aortic valve repair. In eight patients, reimplantations of aortic valve (David procedure) (Fig. 3) were done. In two patients, isolated aortic root remodeling (Yacoub procedure) (Fig. 4) and in seven patients, Yacoub procedure with concomitant aortic annulus remodeling, i.e. implantation of extraaortic flexibile ring CoroNéo (Fig. 5) were performed. The

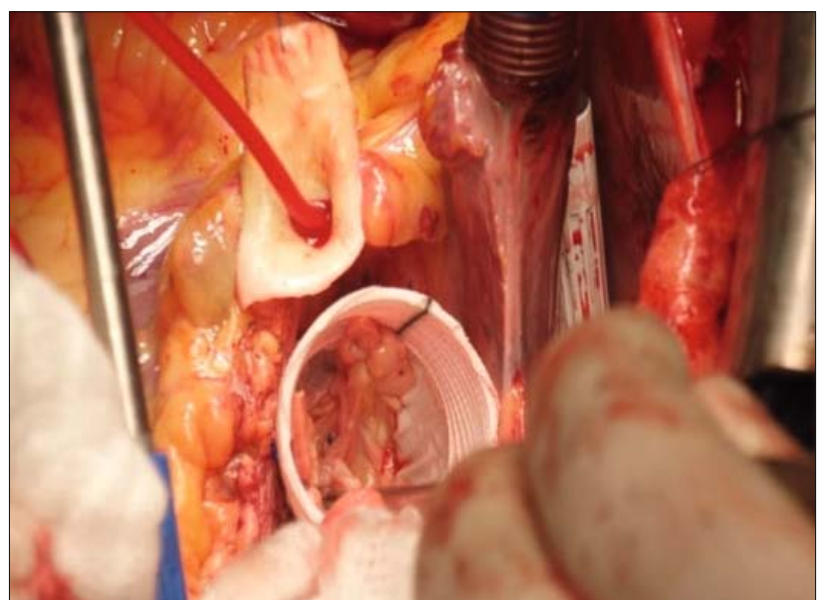

Fig. 3. Perioperative picture of aortic valve reimplantation (David procedure) (Clinic of Cardiac Surgery, VÚSCH, Inc., Kosice, Slovak Republic). 


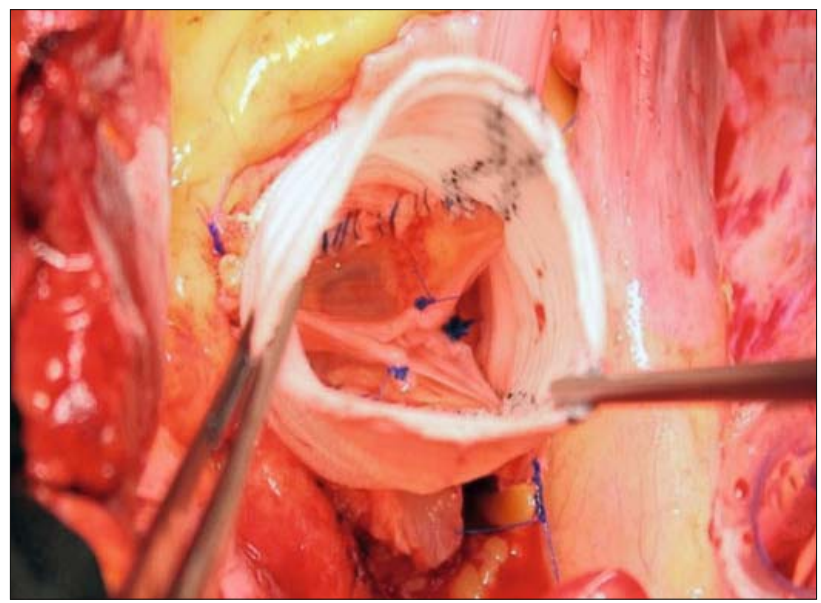

Fig. 4. Perioperative picture of simple aortic root remodeling (Yacoub procedure) (Clinic of Cardiac Surgery, VÚSCH, Inc., Kosice, Slovak Republic).

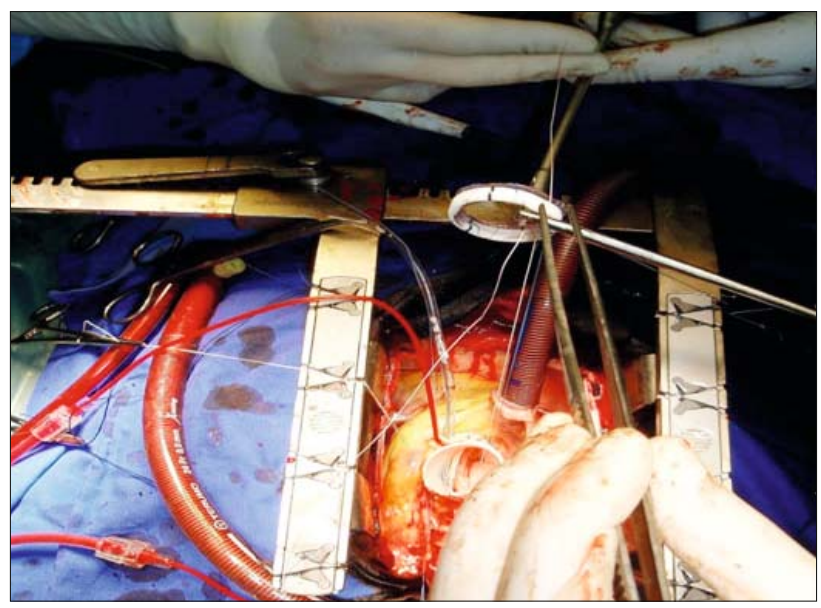

Fig. 5. Perioperative picture of aortic root remodeling (Yacoub) combined with implantation of extraaortic flexible ring (Clinic of Cardiac Surgery, VÚSCH, Inc., Kosice, Slovak Republic).

aortic root-sparing procedure and concomitant aortic cusps repair were performed in nearly all cases. Five patients without aortic root or ascending aorta dilation underwent isolated aortic valve repair. The partial or total resection with aortic arch replacement was associated in eight cases.

\section{Statistical analysis}

By evaluating and comparing the subgroups A1/B1 and A2/ $\mathrm{B} 2$, all patients operated on during the period observed while matching the inclusion criteria for each subgroup were included in the analysis. By evaluating and comparing subgroups A3/B3, all patients with observed parameters, operated on during the period were included in A3 subgroup. By using statistical analysis of propensity score matching for the purposes of statistical comparability, out of the total of ten patients, five patients were selected into subgroup B3.

Individual data were presented as a mean \pm standard deviation (SD). Results of each subgroup were compared by paired or unpaired T-test. For comparing each subgroup, the ANOVA test was used. The quantitative data were compared by $\chi 2$ test. The statistical difference at $\mathrm{p}<0.05$ was considered significant.

\section{Results}

All data were compared among the subgroups, i.e. A1 versus $\mathrm{B} 1, \mathrm{~A} 2$ versus $\mathrm{B} 2$, and $\mathrm{A} 3$ versus $\mathrm{B} 3$.

\section{Data analyzed or evaluated during hospitalization}

Evaluated parameters and results in each subgroup are shown in Table 5. Each parameter evaluated is commented as follows:

\section{Mortality}

One patient died in subgroup A1. The aortic valve and root repair were successful; the cause of death was probably due to severe mitral regurgitation that was underestimated in the preoperative period. Three patients died in subgroup B1 due to significant bleeding from proximal sutures following hemorrhagic shock was the cause, and in one case due to myocardial ischemia due to the left coronary artery blockage. There was a statistically significant difference $(p=0.02)$. One patient died in subgroup A2 due to multiple organ dysfunction during acute aortic dissection, which was the main diagnosis. On the other hand, there is a significant increase in mortality in subgroup B2, where seven patients died. The main reasons were bleeding, progression of dissection, and more extensive surgical procedure. There was a statistically significant difference $(\mathrm{p}<0.001)$. No mortality occurred in subgroups A3 and B3. Results of mortality are shown in Figure 6.

\section{Duration of hospitalization}

There was no significant difference in duration of hospitalization in subgroups A1/B1 and A2/B2. The longest duration of hospitalization related to the main diagnosis (acute aortic dissection) and higher survival was in subgroup A2, compared to subgroup B2. The duration of hospitalization was longer in subgroup A3 compared to subgroup B3.

\section{Duration of extracorporeal circulation}

There was no significant difference in duration of extracorporeal circulation in subgroups A1/B1. A significant difference was

Tab. 5. Comparison of parameters before discharge i particular subgroups.

\begin{tabular}{|c|c|c|c|c|c|c|c|c|c|}
\hline & A1 & B1 & $\mathrm{p}$ & $\mathrm{A} 2$ & B2 & $\mathrm{p}$ & A3 & B3 & $\mathrm{p}$ \\
\hline Mortality (\%) & $1(4.3)$ & $3(13.0)$ & 0.02 & $1(10)$ & $7(70)$ & 0.001 & 0 & 0 & - \\
\hline Hospital lenght (days) & $14.1 \pm 5.8$ & $16.3 \pm 8$ & 0.15 & $23.9 \pm 16.4$ & $18 \pm 4.6$ & 0.29 & $12.6 \pm 4.6$ & $8.6 \pm 0.5$ & 0.04 \\
\hline Duration of extracorporeal circulation (minutes) & $173.4 \pm 44.9$ & $164.6 \pm 68$ & 0.28 & $194.9 \pm 36.2$ & $320.6 \pm 143.2$ & 0.01 & $105 \pm 35.5$ & $154.8 \pm 63.4$ & $<0.0001$ \\
\hline Duration of cardiac arrest (minutes) & $147.9 \pm 44.6$ & $129.8 \pm 47$ & 0.09 & $106 \pm 26.7$ & $151.4 \pm 61.2$ & 0.02 & $84.6 \pm 25.5$ & $113.4 \pm 48$ & 0.02 \\
\hline
\end{tabular}




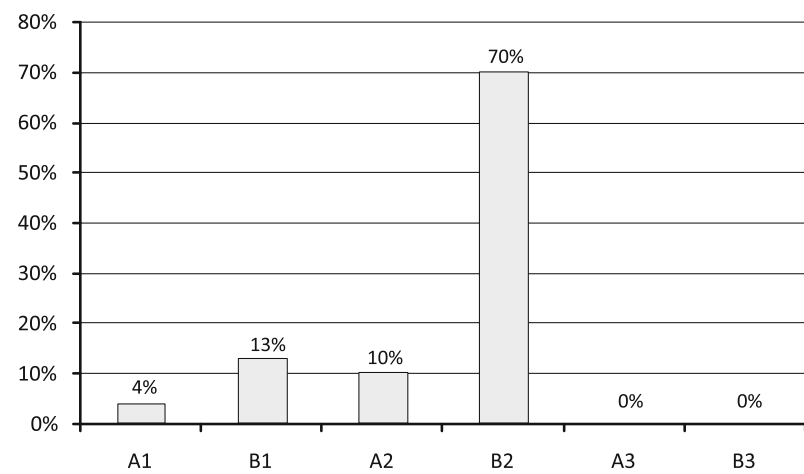

Fig. 6. Early mortality ( 30 day; \%). A1, A2, A3 - A subgroups; B1, B2, B3 - B subgroups

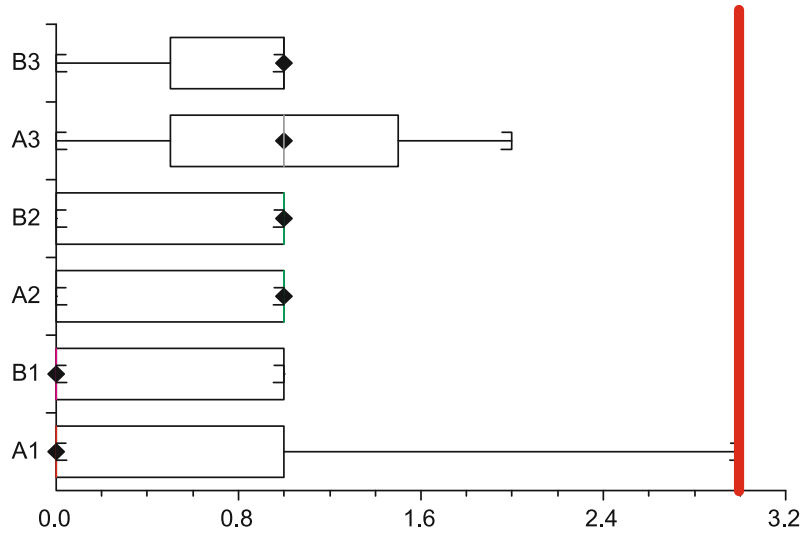

Fig. 7. Postoperative grade of residual aortic regurgitation. A1, A2, A3 - A subroups; B1, B2, B3 - B subgroups.

observed between subgroups A2 and B2 $(\mathrm{p}=0.01)$. The longest duration of extracorporeal circulation related to the preparation of aortic root, root replacement due to more severe form of aortic dissection, and surgical treatment of postoperative bleeding complications was in subgroup B2. A significant difference was found in subgroup B3 compared to subgroup A3 ( $p<0.0001$ ), where the longer time was caused by three reoperations in subgroup 3 .

\section{Duration of cardioplegia}

Duration of cardiac arrest depends on total duration of extracorporeal circulation. There was no significant difference in longer duration of cardioplegia related to more difficult surgical technique in subgroup A1 compared to subgroup B1. There was a significant difference in duration of cardioplegia due to extensive surgery and more severe form of aortic dissection in subgroup B2 $(p=0.02)$. The duration of cardiac arrest was significantly longer in group B3 compared to group A3 due to three reoperations in subgroup B3 $(\mathrm{p}=0.02)$.

\section{Follow up parameters}

Data obtained from examination of patients in each subgroup during the follow up after discharge from hospital are shown in Table 6 . All patients were checked in the follow-up period.

\section{Residual postoperative aortic regurgitation grade}

The grade of residual aortic regurgitation was evaluated in the range from 0 to 4 . The incidence of residual aortic regurgitation was higher in subgroup A1 ( $\mathrm{p}=0.03)$, compared to subgroup B1. In two cases, it was related to aortic valve repair failure, where the severity of residual aortic regurgitation was 3 . In the first patient, the residual aortic regurgitation occurred during the peroperative period, i.e. before the end of operation. The extent of residual aortic regurgitation was probably underestimated by transesophageal echocardiography, by which it was concluded that the aortic regurgitation was up to the degree of 1 . On the first postoperative day, echocardiography confirmed AR to be of degree 3 . The second patient was admitted to the hospital due to heart failure. Three months after the operation, AR of degree 3 was confirmed. A fissure in the native anterior (fused) aortic leaflet was the cause. Both patients were indicated for reoperation with aortic valve and root replacement. In the postoperative period, no significant changes were observed. Therefore patients were released into outpatient care. The regurgitation on aortic prosthesis is generally minimal, or if severe, it is caused by prosthetic valve endocarditis or structural failure of the aortic leaflets in case of biological prosthesis.

This time, eighteen patients in subgroup A1 suffered from minimal or up to 1 aortic residual regurgitation. Three patients had AR 2, i.e. mild aortic regurgitation. There was no difference in residual AR in subgroups A2 and B2. In subgroup A2, all patients had AR up to 2. There was minimal difference in subgroups A3 and B3. In subgroup A3, four patients had minimal, i.e. up to 1 AR. One patient had AR of 2. The results of postoperative residual aortic regurgitation are shown in Figure 7.

\section{Postoperative peak gradient.}

A significantly lower peak gradient was observed, generally, in subgroup A1 ( $<0.0001)$, and subgroups A2 $(p=0.02)$, and A3 $(p=0.004)$, hence in patients after the aortic valve repair. It was related to a less effective area of the mechanical prosthesis

Tab. 6. Comparison of parameters at follow-up in particular subgroups.

\begin{tabular}{|c|c|c|c|c|c|c|c|c|c|}
\hline & A1 & B1 & $\mathrm{p}$ & A2 & B2 & $\mathrm{p}$ & A3 & B3 & $\mathrm{p}$ \\
\hline Grade of AR (0-4) & $0.7 \pm 0.9$ & $0.3 \pm 0.5$ & 0.03 & $0.6 \pm 0.5$ & $0.6 \pm 0.6$ & 0.5 & $1 \pm 0.7$ & $0.8 \pm 0.4$ & 0.3 \\
\hline Peak gradient $(\mathrm{mmHg})$ & $7.8 \pm 8.9$ & $24.5 \pm 12.4$ & $<0.0001$ & $8.4 \pm 6.6$ & $18.3 \pm 7.6$ & 0.02 & $10.4 \pm 10$ & $24.8 \pm 7$ & 0.004 \\
\hline Thromboembolism/bleeding (\%) & 0 & 0 & - & 0 & 0 & - & 0 & $1(20)$ & 0.29 \\
\hline Prosthetic/native valve endocarditis (\%) & 0 & $3(13.4)$ & 0.07 & 0 & 0 & - & 0 & $2(40)$ & 0.11 \\
\hline Reoperation $(\%)$ & $2(8.7)$ & $3(13.4)$ & 0.63 & 0 & 0 & - & 0 & $3(60)$ & 0.03 \\
\hline
\end{tabular}

AR Grade: 0 - trivial, 1 - mild, 2 - moderate, 3, 4-severe 
compared to native-aortic valve repair. Peak gradient is an important parameter, which is related to reverse remodeling of the left hypertrophic ventricle.

Incidence of thromboembolic and bleeding complications.

During our follow- up period, of all groups of patients, only one case of thrombosis of mechanical aortic prosthesis was observed, namely in subgroup B3.

\section{Incidence of native and prosthetic endocarditis.}

Comparing subgroups A1 with subgroup B1, postoperative endocarditis occurred only in three patients in subgroup B1. The difference was not statistically important. No incidence of postoperative endocarditis was recorded in any of subgroups A2 and B2. Out of subgroups A3 and B3, the incidence of this complication appeared in subgroup B3, namely in two patients who were subsequently reoperated.

Incidence of reoperation or need for hospitalization due to cardiac reasons.

There were two patients reoperated in subgroup A1, namely due to aortic valve repair failure (as mentioned above in section dealing with residual postoperative aortic regurgitation grade). In subgroup B1, there were three patients reoperated due to prosthetic endocarditis of the mechanical conduit after aortic root replacement. There were three patients reoperated in subgroup B3, as well. In two patients, the reoperation was done due to prosthetic endocarditis, in one case it was by reason of thrombosis of the mechanical replacement.

\section{Discussion}

In the past 30-40 years, the mitral valve repair surgery due to mitral regurgitation has become part of the routine clinical practice, whereas the mitral valve replacement has become less frequent in association with this indication. On one hand, the expansion of these treatments was possible owing to standardization of surgical techniques, while on the other hand it could take place by virtue of reliable and reproducible results $(14,15)$.

A critical milestone for the development of mitral valve repair was the development of transparent classification by Professor Carpentier. The nomenclature used in Carpentier's classification has generated a common communication tool for clinical cardiologists, echocardiographers and cardiac surgeons (15).

Better understanding of the aortic root functional anatomy supported by surgeons, and encouraging results of reconstructive mitral valve surgery in the period of the past decade have contributed significantly to the progress of implementing new surgical techniques in reconstructive aortic valve and root surgeries. Results in aortic valve and root-sparing operations have to be compared with those of aortic valve and root replacements, respectively.

Complications associated with valve replacement are generally known. They are associated with either anticoagulation therapy side effects and thus with valve prosthesis thrombogenicity, or with an increased risk of the incidence of prosthesis endocarditis.
After $10-15$ years, the biological prosthesis is associated with an increased risk of progressive failure in its function due to degeneration processes. The aortic valve replacement brings on a negative impact on hemodynamics. The effective orifice area decreases (prosthesis area is always smaller than that of native valve of the same annular diameter), and is associated with an increase in aortic valve flow pressure gradients. Higher flow pressure gradient may have a negative impact on reverse remodeling of eccentric hypertrophy of the left ventricle $(16,17)$.

One of the three randomized studies dealing with incidence of complications after aortic and mitral valve replacements and simultaneously comparing differences between the types of used prosthesis is the Veterans Affairs randomized trial published in 2000. The results after 15 years of observations were surprising. The complications associated with valve prosthesis implantation (mechanical or biological) occurred in nearly $60 \%$ of patients (10).

Takkenberg et al published 1998-2010 global meta-analysis results of all trials evaluating the incidence of postoperative complications after Bentall operation and aortic root repair. Summaries of 15 papers were published. The study analyzed the results of Bentall operation performed on 4,713 patients. Further, seven papers were published on 1,389 patients after aortic root repair. The basic demographic data were comparable in both groups. Primary endpoint parameters were observed as follows: incidence of thromboembolic, thrombogenic and bleeding complications in patients on anticoagulation therapy. The third main endpoint of observation was reoperation. There were $98.7 \%$ of patients without thromboembolic events and $99.9 \%$ of patients without bleeding complications in the group of aortic valve and root-sparing operations after 10 years. After Bentall operation, 91\% of patients had no observed complications. The difference was statistically significant (18).

During the period of the past five years, professor Schäffers from Homburg has become definitely the most published and cited author in the field of aortic root repair. While being the author of several innovations in surgical techniques of the aortic root repair, he has the largest group of operated and observed patients. The results published by Schäffer et al. can possibly be considered the ,reference“ results. In 2010, he presented the results of 640 patients after aortic valve and root-sparing operations collected from ten years of observation. There were $95 \%$ of patients without thromboembolic and bleeding complications, and $97 \%$ of patients without infective endocarditis (19).

The results of the aortic valve and sparing operations achieved at our Clinic are comparable with the results published in literature. In spite of the fact that due to higher technical difficulty, the total operating time and duration of the extracorporeal circulation and cardiac arrest period are longer in the group of patients after the sparing operation, we demonstrated lower mortality and morbidity in the group of patients after elective aortic ascending aneurysm surgery. The longer operating time and duration of extracorporeal circulation represents one of the potential limitations to the methodology, which has to be considered in choosing and indicating the surgical strategy. Older and polymorbid patients can tolerate 
longer operating time as well as longer extracorporeal circulation. Therefore in latter patients, a shorter and simpler type of operation has to be chosen, such as aortic valve or root replacement.

In the group of patients operated urgently due to acute aortic ascending dissection, the difference in mortality after aortic root repair compared to that after Bentall operation was even more significant $(10 \%$ vs $70 \%$; $=0.001)$. Paradoxically, in the most of patients with acute aortic ascending dissection, the sparing surgery is shorter than the replacement according to Bentall. It is due to aortic wall damage involvement in the dissection, and reimplantation of dissected coronary arteries, which are often extremely technically difficult. The limitation to aortic dissection lies in the potential risk of re-dissection in the future, especially once only a part of the wall is repaired rather than replaced during the operation. The answer to this question is to be found based on longterm follow-up period of patients after aortic ascending dissection repair. There was no re-dissection in our group of patients during the follow-up period. This is however a small group of patients and short to mid-term follow-up period, thus it is impossible to derive relevant conclusions.

In accordance with literature we can state that we consider the sparing operation to be a good choice in case of normal leaflets movement, aortic valve regurgitations caused by flailing leaflet or when leaflets fall into the left ventricle during diastole. According to literature, restrictive leaflets motion is considered to be a relative contraindication to repair surgery.

Specific problems arise in patients with isolated aortic regurgitation with a physiologically functioning aortic root. Opinions on repair in these patients are ambiguous in literature. A paper on the largest group of patients after isolated aortic valve repair has been published by Schäffer et al (9). He has shown satisfactory results, and our experience observed in this group fully confirms his conclusions. It is necessary to realize that the results of isolated aortic valve repair should be compared with isolated aortic valve replacement results, while the latter is connected with standard mortality of less than $1 \%$ in developed workplaces. This puts forward extremely high demand on the "perfection" of repair.

Based on our own experience, we can confirm that one of the conditions to be most importantly met in surgical technique is the achievement of a sufficiently effective position of the leaflets as well as that of sufficient coaptation $(26,27)$.

We definitely consider the use of the instrument of aortic caliper (the Fehling Instruments $\mathrm{GmbH} \& \mathrm{Co}$. KG, Germany) designed and subsequently popularized by professor Schäffers, to be optimal. In the first phase of the implementation of surgical aortic valve repair into practice, we have tried it on ourselves as to how difficult it is to achieve a permanent and sufficient coaptation with eyeballing methodology only. The implementation of "caliper" into surgical armamentarium meant a breakthrough moment in standardization and reproducibility of our surgical technique.

Our study has a limitation to it, namely based on the fact that it is retrospective. In the future, any possible implementation of a prospective study will require close cooperation with cardiologist for the purpose of early diagnosis as well as early indication for surgery in patients with aortic regurgitation. Further limitation to this paper is that we have compared supracoronary replacement of ascending aorta including aortic valve repair in subgroup A2 with more extensive Bentall procedure in subgroup B2. The reason lied in the need to evaluate the patients' status in the follow-up period. We have been looking for answers to two questions, namely (1) as to whether the supracoronary replacement itself is a satisfactory surgical procedure for patients with acute aortic dissection comprising ascending aorta and aortic root, and (2) whether we will face re-dissection or dilatation of primary "weak" aortic wall of the root in the future. As mentioned above, all patients in A2 and B2 subgroups were eligible to undergo either root replacement or supracoronary replacement combined with valve repair.

A further limitation to our work lies in a relatively small number of patients. It is evident in comparison between subgroups A3 to B3. In general, it is possible to state that the number of isolated aortic valve repairs compared to aortic root repairs is smaller in younger patients. In addition, also based on the relatively limited number of patients, it is necessary to consider our conclusions to be of preliminary character only. Based on the achieved results with aortic valve and root-sparing surgical techniques, we expect that in the near medical future, the conclusions hereby drawn by us will be confirmed either partially or in full.

\section{Conclusion}

Based on our first experience and mid-term results, in spite of high technical difficulty, we consider aortic valve and root sparing surgeries to be operations without an increase in postoperative morbidity and mortality. We are of the opinion that these operations in indicated cases are an interesting therapeutic alternative, potentially advantageous for younger patients, patients with active lifestyle and women at childbearing age. In addition to leaflets of aortic regurgitation, we consider the sparing operations to represent a method of choice.

The variety of patients indicated for aortic regurgitation surgery has changed in the past period. In the past, only patients with the aortic root aneurysm used to undergo this operation. A minimum number of patients were operated due to isolated aortic regurgitation. In addition, also aortic root procedures were not supplemented with valve leaflet or aortic annulus procedures. In contrast, the numbers of patients with surgically treated bicuspid aortic valve as well as those of patients indicated for aortic root and aortic valve-sparing operations have increased recently.

Once the surgeon wants to achieve standard high quality results, it is necessary for him to manage the techniques of aortic valve and sparing operations. The results of aortic valve repairs are compared to those of mitral valve repairs. The risk of complications directly associated with valve repair is low, while for the most of patients with aortic regurgitation, the method is appropriate. Equally important is the centralization of patients at one workplace. In case of proper indication and optimal surgical technique, the mid-term operative results are good and improve the quality of life. 


\section{References}

1. Popelová $\mathbf{J}$ et al. Doporučené postupy pro diagnostiku a léčbu chlopenních srdečních vad v dospělosti. In Cor et Vasa 2007; 49 (7-8).

2. Vahanian A et al. Guidelines on the management of valvular heart disease. The Task Force on the Management of Valvular Heart Disease of the European Society of Cardiology. Eur Heart J 2007; 28 (2): 230-268.

3. Bonow R et al. ACC/AHA guidelines for the management of patients with valvular heart disease: a report of the American College of Cardiology/American Heart Association Task Force on Practice Guidelines. J Amer Coll Cardiology, 2006; 48 (3): 1-148.

4. Lansac $\mathbf{E}$ et al. A lesional classification to standardize surgical management of aortic insufficiency towards valve repair. Eur J Cardio-thorac Surg 2008; 33 (5): 872-878.

5. EI Khoury G et al. Functional calssification of aortic root/valve abnormalities and their correlation with etiologies and surgical procedures. Current Opinion in Cardiology 2005; 20): 115-121.

6. David TE et al. Aortic valve preservation in patients with aortic root aneurysm: results of the reimplantation technique. Ann Thorac Surg 2007; 83 (2): 732-735, discussion 785-790.

7. Cohn LM. Cardiac Surgery in the Adult. III. Edition. London: McGrawHill Medical, 2007. $1704 \mathrm{~s}$

8. Pacini D et al. Early results of valve-sparing reimplantation procedure using the Valsalva conduit: a multicenter study. Ann Thorac Surg 2006; 82 (3): 865-871.

9. Aicher $D$ et al. Cusp repair in aortic valve reconstruction: does the technique affect stability? J Thorac Cardiovasc Surg 2007; 134 (6): 1533-1538.

10. Hammermeister $\mathbf{K}$ et al. Outcomes 15 years after valve replacement with a mechanical versus a bioprosthetic valve: final report of the Veterans Affairs randomized trial. J Amer Coll Cardiol 2000; 36 (4): 1152-1158.

11. Aicher $\mathbf{D}$ et al. Aortic root remodeling: ten-year experience with 274 patients. J Thoracic Cardiovasc Surg 2007; 134 (4): 909-915.

12. David TE et al. Long-term results of aortic valve-sparing operations for aortic root aneurysm. J Thorac Cardiovasc Surg 2006; 132 (2): 347-354.

13. Yankah CA, Weng Y, Hetzer R. Aortic Root Surgery - The Biological Solution. Berlin: Springer Medizin, 2010, 616 p.
14. Duran CG et al. Clinical and hemodynamic performance of totally flexible prosthetic ring for atrioventricular valve reconstruction. Ann Thorac Surg 1976; 22: 458-463.

15. Carpentier A. Cardiac valve surgery - the „French correction“. J Thorac Cardiovasc Surg 1983; 86: 323-337.

16. Čerbák R.. Nejčastejší chlopenní vady. Praha: Galén, 2007, 188 s.

17. Dominik J.. Chirurgie srdečních chlopní. Praha: Grada, 2008, 368 s.

18. Takkenberg $\mathrm{H}$ et al. Aortic valve repair. Is it worthwhile? Aortic valve repair meeting. Paris, France, 2011.

19. Aicher $D$ et al. Aortic valve repair leads to a low incidence of valverelated complications. Eur J Cardio-thorac Surg 2010; 37: 127-132.

20. Yacoub MH et al. Late results of a valve-preserving operation patients with aneurysms of the ascending aorta and root. J Thorac Cardiovasc Surg 1998; 115 (5): 1080-1090.

21. Luciani GB et al. A Recurrence of aortic insufficiency after aortic root remodeling with valve preservation. Ann Thorac Surg 1999; 67: 1849-1852.

22. Lansac $\mathbf{E}$ et al. Aortic prosthetic ring annuloplasty: A useful adjunct to a standardized aortic valve sparing procedure? Eur J Cardio-thorac Surg 2006; 29 (4): 537-544.

23. De Paulis $\mathbf{R}$ et al. Opening and closing characteristics of the aortic valve after valve-sparing procedures using a new aortic conduit. Ann Thorac Surg 2001; 72: 487-494.

24. Soncini $M$ et al. Aortic root performance after valve sparing procedure: A comparative finite element analysis. Med Engin Phys 2009; 31: 234-243.

25. Lansac $\mathbf{E}$ et al. An aortic ring to standardise aortic valve repair: preliminary results of a prospective multicentric cohort of 144 patients. Eur J Cardio-thorac Surg 2010; 38: 147-154.

26. Schäfers HJ et al. A new approach to the assessment of aortic cusp geometry. J Thorac Cardiovasc Surg 2006; 132: 436-438.

27. Vojacek $\mathbf{J}$ et al. Options reconstructive procedures patients with bicuspid aortic valve. Cor Vasa 2010; 52: 523-530.

28. Nataf $P$ et al. Dilation of the thoracic aorta: medical and surgical management. Heart 2006; 92 (9): 1345-1352.

Received December 19, 2012. Accepted February 28, 2014. 